\title{
Study on the Relationship between Heterogeneity and Entrepreneurial Performance of College Recruited Entrepreneurs Team
}

\author{
Sida Hong ${ }^{1}$,Mengxue $\mathrm{Yu}^{2}$ \\ ${ }^{1}$ department of economics, Zhejiang university, Zhejiang province, China \\ ${ }^{2}$ department of management, Zhejiang university, Zhejiang province, China
}

Keywords: Heterogeneity;Team Atmosphere;Entrepreneurial Performance; College Recruited Entrepreneurs

\begin{abstract}
In present internet era, in order to conform to the new trend of public entrepreneurship and innovation, universities and colleges positively support the development of recruited entrepreneurs, as a result, the college entrepreneurs are thriving like mushrooms after rain. During the formation of recruited entrepreneurs team, the members with heterogeneity are considered a advantage of complementary strength to promote entrepreneurial performance. However, some scholars believe that team heterogeneity restrains entrepreneurial performance. In order to reveal the"black box" of the mechanism of the effect of team heterogeneity on entrepreneurial performance, based on uniqueness of the college team, we divide heterogeneity into internal heterogeneity and external heterogeneity, and we take team atmosphere as a mediation variable in present research. Taking a large amount of recruited entrepreneurs teams from Shandong universities and colleges as samples of the survey, it has proved that external heterogeneity can positively affect team atmosphere, thus promoting entrepreneurial performance; while internal heterogeneity can reversely affect team atmosphere, thus counting against entrepreneurial performance.
\end{abstract}

\section{Introduction}

Promoting public entrepreneurship and innovation, is also the source of development, the road of fairness, and the strategy of enhancing the power of the country, and it has a great significance for economic restructuring, creating new engines of development, improving the driving force of development, taking an innovation-driven path of development. In February 2015, "Creating public space for entrepreneurship" as a policy was identified in the state council executive meeting, and put up a new platform for innovation and entrepreneurship. With the rising recruited entrepreneurs campaign, college students have become the most active and creative group of the recruited entrepreneurs.

Based on the insufficient previous study, we will explore the effects of different types of heterogeneity on entrepreneurial performance in the paper. On the other hand, according to various views of present scholars, we divide team atmosphere into 4 dimensions, including long-term goals, participating safety, task guidance, and innovation support; and study the intrinsic relationship between the recruited entrepreneurs heterogeneity, team atmosphere, and entrepreneurial performance, in order to reveal the" black box" between the recruited entrepreneurs and entrepreneurial performance. 


\section{Review the literature}

As for the definition of a team atmosphere, a more representative view is proposed by Tagi in 1968 that team atmosphere is a feature of an organization's internal environment. It's testable. This feature has reciprocal effects among internal members. When members' perception of the team atmosphere is good, the efficiency and satisfaction will be improved, on the contrary, when the perception of team atmosphere is bad, higher turnover rate will appear in the future development process.

Team atmosphere is the feature manifested in the interaction process between the individuals and the team. Many scholars have found that the team atmosphere is influenced greatly by heterogeneity.

The relationship between team atmosphere and entrepreneurial performance. According to Weiss and Cropanzano's (1996) affection events theory, the emotion in the work is determined by the specific events in the work. The stuff's emotions response to the occurring events, further influencing their job performance and satisfaction degree. Similar to individual, the team will develop a shared attitude, behavior pattern, and emotional reactions responding to the shared experiences or events, which will further affect team members' behavior and performance. The shared experiences and shared perception towards the team's emotion as well as the exchange of their emotions. This perception stands for the characteristic of the team, and has a significant impact on the team and team members ( Liu et al, 2008), that is the team emotional atmosphere. For example, a research team developed a new product, which can bring positive team emotional atmosphere ; or a sports team lost the game, then the team will have a negative emotional atmosphere. According to Cohen and Bailey's (1997) team effectiveness heuristic model, team emotional atmosphere, as the psychological characteristics of the group is bound to affect the team effectiveness by influencing individual feelings or emotional labor implementation. On the one hand, team emotional atmosphere can affect the emotion and motivation; on the other hand, by influencing the team interaction behavior, it has an influential effect on the creation of the individual and the overall team ( Long Zengliang, Tang Chaoying, 2009).

\section{Classification of heterogeneity and hypothesis}

As for the dimensions of heterogeneity, the study draws lessons from Jackson et al's (2003) study, according to the degree of heterogeneity measuring difficulties, divide recruited entrepreneurs team heterogeneity into external heterogeneity and internal heterogeneity. External heterogeneity refers to demographic statistical characteristics, such as gender, age, ethnicity, experience, educational level and professional background, and so on, which are easy to observe and measure. While the internal heterogeneity is characteristics which are not easy to observe and measure, most of which are heterogeneity among team members resulting from differences based on value, cognition, attitude, and preferences.

As for college recruited entrepreneurs team, members' external heterogeneity affects significantly on atmosphere. College recruited team is typically made up of undergraduates, graduate students, as well as graduates with heterogeneity of age, educational level, professional background, and experiences, which can improve the method of solving problems and enrich the source of information. It's beneficial for team members to complete the task in sense of participation and confidence; it's helpful for the team to identify the vision and support innovation within the team; ultimately contributing to formation of positive, cooperative, and innovative team atmosphere. Based on the above analysis, we propose a hypothesis:

H1: External heterogeneity( age, educational level, professional background) can positively affect 
team atmosphere.

There is internal heterogeneity among members in college recruited entrepreneurs team. Different members have different values, ways of thinking, and acting styles. For example, parts of team members think the team goal is hard to understand, and they think others' work is meaningless, and unwilling to communicate with those holding different views, those behavior can bring bad influence to team atmosphere. Based on this, we suggest another hypothesis: H2: Internal heterogeneity ( e.g. values, ways of thinking, acting styles) negatively affects team atmosphere.

Good team atmosphere is the prerequisite for recruited entrepreneurs team to survive and develop. Firstly, if any organization wants to succeed in the fierce competition, it needs to set up the vision to identify the specific tasks for team members to complement, and it also needs to refine the objective for each member, so as to enhance the sense of responsibility of team members, which is the catalyst of continues development for the enterprise; secondly, human resource is the core element for the entrepreneurial enterprise. A good team atmosphere can create a relaxed, harmonious, and friendly interior environment, which can ensure effective communication between members, enhance their sense of belonging and satisfaction, further generating a motivation to work hard; thirdly, a good task oriented atmosphere ensures the members to deal with the difficulties within work through cooperation, and make the members observe the team and their own weakness with a more objective perspective, so as to enhance the effectiveness of work; finally, low performance of some college recruited entrepreneurs teams lies in that, the members can't share information and technology, resulting in lagging innovation capabilities. A good innovation supportive atmosphere can make the members share more systematic and practical knowledge, and encourage the members to perform multiple angle and innovative thinking, to improve the efficiency of cooperation. Thus, we propose the following hypothesis:

H3: Recruited entrepreneurs team atmosphere (vision, participation security, task orientation, innovation support) can positively impact on entrepreneurial performance.

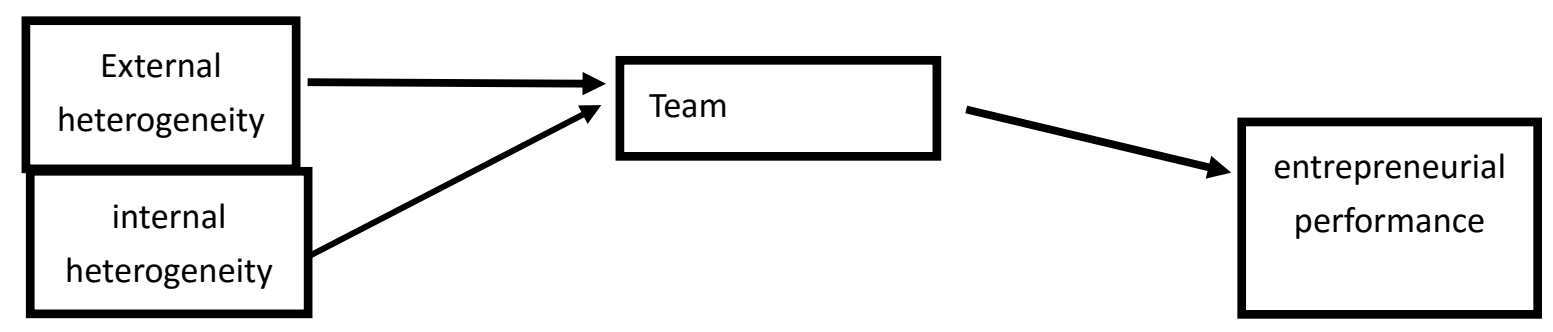

Figure 1. Conceptual model

\section{Study design.}

The research methods used in this study are mainly in-depth interviews and questionnaire. The in-depth interviews are carried out among Shandong college recruited entrepreneurs teams and recruited entrepreneurs' space supportive units. Through the interview, we found that the main problems the recruited entrepreneurs teams in this province face. Based on these survey results, we prepare relevant questionnaire, with a large sample of questionnaire passed to the survey objects of Shandong recruited entrepreneurs teams, and collect valid research data. This study belongs to applied research, so the interviews to the participants go throughout the overall course of study. The survey questionnaire of college recruited entrepreneurs teams mainly involved team statistical information, the team structures, team atmosphere, team performance, team environment, their own problems, and the like. In the survey, 300 pieces of questionnaire were passed, and 241 valid were collected, the response rate is $80.3 \%$. 
In the study, we use foreign mature scales as tools for data collection, shown in Table 1, applying Cronbach's a consistency coefficient to test the reliability. It's found that each variable scale has high reliability. In order to make the empirical structure with greater reliability, in the research, we introduce the firm size and age as control variables. All relevant variables involved in the measure apply Likert 7-level scale, with 1 point for" completely disagree" and 7 poits for" completely agree"

Table 1 the resource of scale with various research variables, and reliability testing results

\begin{tabular}{|c|c|c|c|c|}
\hline Variables & specific dimension & $\begin{array}{l}\text { the source of } \\
\text { scale }\end{array}$ & $\begin{array}{l}\text { avalue for each } \\
\text { dimension }\end{array}$ & Cronbach's $\alpha$ \\
\hline \multicolumn{2}{|c|}{$\begin{array}{l}\text { Recruited entrepreneursExternal } \\
\text { team heterogeneity } \quad \text { heterogeneity }\end{array}$} & $\begin{array}{c}\text { Jehn,North } \\
\text { craft,Neale } \\
\text { (1999) }\end{array}$ & 0.815 & 0.828 \\
\hline & $\begin{array}{l}\text { Internal } \\
\text { heterogeneity }\end{array}$ & & 0.872 & \\
\hline \multirow[t]{4}{*}{ Team atmosphere } & Vision & & 0.825 & 0.952 \\
\hline & $\begin{array}{l}\text { Participation } \\
\text { security }\end{array}$ & $\begin{array}{c}\text { Anderson, } \\
\text { West }\end{array}$ & 0.869 & \\
\hline & Task orientation & (1998） & 0.785 & \\
\hline & Innovation support & & 0.947 & \\
\hline \multirow[t]{3}{*}{$\begin{array}{l}\text { Entrepreneurial } \\
\text { performance }\end{array}$} & Market share & & 0.888 & 0.867 \\
\hline & Sales & $\begin{array}{l}\text { Covin,Slevin } \\
\text { (1991) }\end{array}$ & 0.865 & \\
\hline & Net profit & & $\begin{array}{l}0.912 \\
0.846\end{array}$ & \\
\hline
\end{tabular}

\section{Results}

This study uses SPSS18.0 statistical software to collect data for analysis. The descriptive statistics showed that the mean scores of items in question is close to and above the middle level, the standard deviation is also within the reasonable range. The normal distribution of results is above the level of 0.01 , which meets the empirical analysis requirements. In the paper, we use multiple regression analysis to verify the hypothesis, and the results are shown in Table 3 and Table 4. Table 3 shows, the regression coefficient between external heterogeneity and team atmosphere is 0.545 , it's significant above the level of 0.01 , so hypothesis 1 is verified that external heterogeneity can positively affect team atmosphere; the regression coefficient between internal heterogeneity and team atmosphere is -0.218 , and it's significant above the level of 0.01 , so hypothesis 2 is verified that the internal heterogeneity can adversely affect team atmosphere. 
Table 2 the regression analysis results of the relationship between recruited entrepreneurs team heterogeneity and team atmosphere

\begin{tabular}{cccc}
\hline \multirow{2}{*}{ Variables } & model 1 & model 2. & Model 3 \\
\cline { 2 - 4 } & Standard coefficient & Standard coefficient & Standard coefficient \\
\hline Firm size & $0.203^{*}$ & 0.123 & 0.161 \\
\hline Firm age & $0.224^{*}$ & & 0.201 \\
External heterogeneity & & $0.147^{*}$ & \\
Internal heterogeneity & & & \\
R & & $0.545^{* * *}$ & $-0.218^{*}$ \\
R & & & 0.129 \\
Rafter adjustment & 0.083 & 0.369 & 0.103 \\
Value F & 0.066 & 0.351 & $5.113^{* * *}$ \\
\end{tabular}

Table 3 the regression analysis results of the relationship between team atmosphere and entrepreneurial performance

\begin{tabular}{llc}
\hline & \multicolumn{1}{c}{ model 1 } & model 2. \\
\cline { 2 - 3 } Variables & Standard coefficient & Standard coefficient
\end{tabular}

\begin{tabular}{ccc}
\hline Firm size & $0.198 *$ & $0.129 *$ \\
\hline $0.200 *$ & $0.104 *$
\end{tabular}

Firm age

$$
0.369 * * *
$$

External heterogeneity

0.069

0.245

Internal heterogeneity

0.051

$\begin{array}{ccc}\mathrm{R}^{2} & 3.872 * * * & 8.887^{* * *} \\ \mathrm{R}^{2} \text { after adjustment } & 0.198^{*} & 0.129 * \\ \text { Value } \mathrm{F} & 0.200^{*} & 0.104^{*}\end{array}$

Table 4 shows that the regression coefficient between team atmosphere and entrepreneurial performance is 0.369 , and it's significant above 0.01 , so hypothesis 3 is verified that team atmosphere can positively impact on entrepreneurial performance.

\section{Discussions}

In this study, we take college recruited entrepreneurs teams as research objects, try to reveal the impact mechanism of heterogeneity on entrepreneurial performance. Through the research, we believe that team heterogeneity affects entrepreneurial performance by the mediator of team atmosphere, in another word, the relationship between entrepreneurs team heterogeneity and 
entrepreneurial performance can remain stable and sustainable due to the mediating effect of team atmosphere.

In this study, there are still some shortcomings, because many factors can affect entrepreneurial performance, while this article only explores the mediating effect of team atmosphere. So further analysis and identification of the role of other factors are needed in the future studies.

\section{References}

[1]Kamm J B, Shuman J C, Seeger J A, et al. Entrepreneurial teams in new venture creation: A research agenda[J]. Entrepreneurship Theory and Practice, 1990,4(4):

33-38.

[2] Gnyawali D R, Fogel D S. Environments for entrepreneurship development: Key dimensions and research implications[J]. Entrepreneurship Theory and Practice, 1994 (18):43-62.

[3]Lawrence P,Lorsch J.Organizations and Environment[M].Boston:Harvard

University Press,1967.

[4] Li L.The Effects of Trust and Shared Vision on In-ward Knowledge Transfer in Subsidiaries, Intra and InterOrganizational Relationships[J].International

Business Review,2005,14:77-95.

[5]Miller D,Friesen P.Innovation in Conservative and Entrepreneurial Firms: Two

Models of Strategic Momentum[J].Strategic Management Journal,1982,3:1-25. 